\title{
Uruguay: identidad y nación en construcción
}

CRISTINA HEUGUEROT*

\begin{abstract}
Resumo: Analisa-se aqui o primeiro número de um jornal chamado de Ilustracón Uruguaya (1883), publicação oficial da Escola de Artes e Ofícios. Reflete-se sobre a origem da "representação social" de Jose Artigas, herói nacional. Investiga-se o processo da construção social e revela-se que essa instituição educativa do Estado (hoje, CETP-UTU), fundada há mais de 130 anos, colaborou ativamente na criação da identidade nacional e na imagem compartilhada sobre o herói.
\end{abstract}

Abstract: A historical document, the first number of a newspaper, Ilustración Uruguya, official publication of the School of Arts and Occupations, of the year 1883, is analyzed. We reflect on the origin of José Artigas's "social representation", and investigate about the process of social construction and try to show that the state educational institution, founded more than 130 years ago (today, CETP-UTU), has collaborated actively to create the national identity and to consolidate the hero's image.

Palavras-chave: Nação. Identidade. Representação social.

Key words: Nation. Identity. Social representation.

\section{A modo de introducción}

"Si no tuviéramos cara no tendríamos vergüenza [...]".1

La reconstrucción del pasado admite múltiples perspectivas de abordaje. Por eso en muchas ocasiones el historiador tiene la necesidad de explicar el proceso de construcción del objeto investigado y las vicisitudes por las que atravesó al realizar su tarea.

Así, quien escribe este artículo considera necesario prevenir al lector de que, partiendo de la base de que la palabra escrita y la comunicación visual tienen gran poder instituyente y un enorme

* Master en Historia, Doctorando de la UBA. Docente de la Facultad de Humanidades y Ciencias de la Educación, Unidad Opción Docencia, Universidad de la República

O. del Uruguay (UDELAR). E-mail: mheuguer@internet.com.uy

1 Todos los acápites han sido extraídos del número de la revista analizada.

Estudos Ibero-Americanos. PUCRS, v. XXXIII, n. 2, p. 76-89, dezembro 2007 
peso en la formación y consolidación del imaginario social, ha creído interesante en el momento actual, el revisar algunos documentos poco conocidos de la historia de nuestra de nuestra organización ${ }^{2}$ (UTU) que presentan la particularidad de acercarnos a ese momento histórico en que confluyeron la identidad institucional y nacional, ambas en proceso de consolidación.

Se trata del primer número de una revista llamada la Ilustración Uruguaya, del 15 de agosto de 1883, que es la primera publicación oficial de la Escuela de Artes y Oficios. ${ }^{3}$

Importa mencionar que de esa revista quincenal se editaron treinta y siete números, hasta el 31 de diciembre de 1885, siempre bajo la Dirección de Nicolás Granada y con la "Administración de Pedro Rodríguez, Alumno del Establecimiento", 4 según se expresa en la portada.

En este documento, además del texto escrito, se analizarán el frontispicio de la revista y una litografía de Artigas $^{5}$ realizada por el pintor Goffredo Ernani Sommavilla, entonces maestro de la Escuela, que contó con la colaboración de alumnos de la institución.

Con el convencimiento de que aquellos aspectos del pasado más significativos no son los que se recuerdan sino los que se olvidan, debemos confesar que nuestro interés por esta fuente documental se despertó al leer una obra de Carlos Olivieri, citada en bibliografía al final de este artículo. En ella, el autor comenta y transcribe literalmente algunos de sus artículos. Sus comentarios nos permitieron entrever que esa publicación, propiciada durante el gobierno de Máximo Santos, era una metáfora, el símbolo de un proceso de construcción consciente de la identidad nacional, ya en etapa de consolidación. ${ }^{6}$

2 Al referirse a "nuestra organización" quiere decir que esta investigación fue realizada en el marco de un proceso de análisis institucional, aún en elaboración. La organización es el Consejo de Educación Técnico Profesional, es decir lo que fue la Universidad del trabajo del Uruguay (UTU), el subsistema de educación técnica media y superior del estado uruguayo.

3 El General Santos, con fecha 31 de agosto resuelve que esta revista sea propiedad de la $\mathrm{E}$ de A y O, nombra su Director y define que no pague franqueo de correos por ser publicación oficial (AUTU, 1883, n. 1 6, folio 146) Esa Escuela de Artes y Oficios, será hoy CETP-UTU.

4 Estos datos que aparecen en portada en números posteriores, han sido corroborados por el Archivo Institucional.

En folio n. 146, del 31 de agosto de 1883, se resuelve que esta revista sea propiedad de la Escuela de Artes y Oficios, decisión que asume Máximo Santos y se agrega además, que "por ser periódico oficial no paga por correos" AUTU, 1883, n. 16.

5 Ver documentos que ilustran el artículo.

6 Importa recordar que el fenómeno del nacionalismo a fines del siglo XIX también está operando con fuerza en muchas partes del mundo. 
Quizás por eso fue significativo descubrir que si bien la Biblioteca Nacional ${ }^{7}$ posee una colección encuadernada y completa de la misma, el archivo institucional no parece haber conservado rastros de ella.

La revista nos informa que la intención de los redactores era sensibilizar a los lectores en temas nacionales y generar un conocimiento compartido sobre hechos y personajes valorados en el país. Era por lo tanto y desde lo explícito, un instrumento estratégico en la conformación de la nación, lo que el propio nombre de la publicación reforzaba en sí mismo, como veremos más adelante.

Sin embargo, los dos elementos visuales mencionados anteriormente muestran todavía, la coexistencia en el país de mundos imaginarios diferentes y contradictorios que se hallaban presentes a la hora de definir las características de nuestra nacionalidad.

La adquisición y desarrollo de una identidad propia es uno de los fenómenos más complejos y fascinantes en el ciclo vital de las personas y las organizaciones humanas.

En ese sentido, la Historia latinoamericana presenta una particularidad, ya que, como bien ha estudiado el historiador José Chiaramonte (1997, p. 164) a diferencia de los procesos europeos, en nuestros países el estado precedió a la nación. Por lo tanto, es posible rastrear en nuestro pasado mecanismos deliberados para impulsar el desarrollo de un sentimiento nacional. Este, surgido en las luchas independentistas de principios del siglo XIX, buscaba ahora consolidarse a través del discurso escrito y visual oficial.

Aunque algunos autores señalan que ese intento consciente de construir los estados nacionales se fomentó principalmente a través de tres mecanismos: el censo, el mapa y el museo (Anderson, 1993, p. 228-229), porque permitió imaginar "la naturaleza de los seres humanos que gobernaba, la geografía de sus dominios y la legitimidad de su linaje", nosotros sabemos que también, las publicaciones oficiales, los textos escritos y visuales reforzaban ese proceso.

7 En relación a la afirmación precedente importa destacar que: a la fecha, en la búsqueda de archivo no hemos podido encontrar el material referido. Tampoco nos han podido informar sobre él otros conocedores del archivo, como Plinio Torres Jean de Dieu o el Archivólogo Alfredo Coirolo. No descartamos que en algún momento pueda aparecer algún ejemplar aislado traspapelado. 


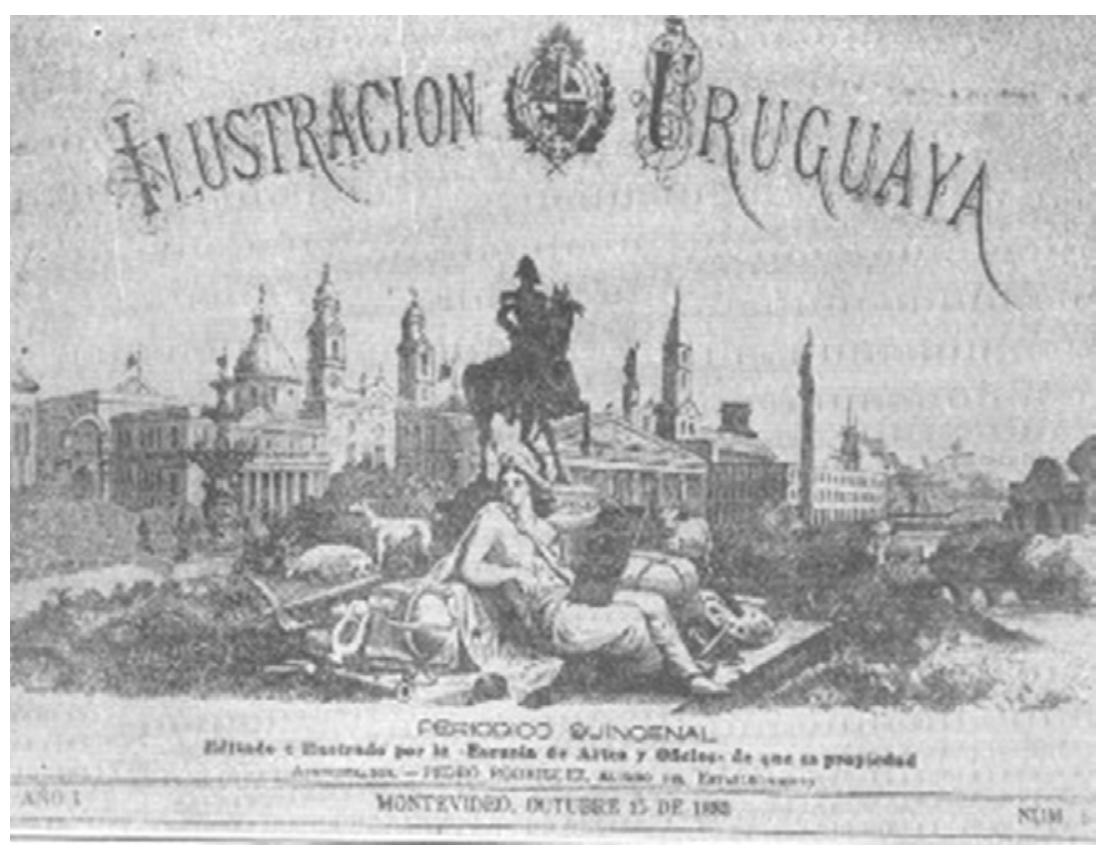

Eso explica la contemporaneidad en la historia nacional de ciertos sucesos como el primer censo (1860), la organización definitiva de la división departamental del país, o el interés por iniciar colecciones de objetos típicos. En definitiva, se relaciona con el peso de la corriente positivista que ha entrado al país con gran fuerza en la época en que se fundó la revista mencionada.

La importancia del museo y la colección ya sea particular o estatal, la introducción de disciplinas como historia nacional y geografía del Uruguay en la currícula de la educación formal de la Escuela de Artes y Oficios, son coincidentes con la aparición de nuevas organizaciones sociales, mutuales y culturales que buscan redefinir espacios de acción públicos y privados.

Conviven las Sociedades de Amigos del país, con organizaciones mutuales que recuerdan el lugar de origen (Europa) a través del apoyo al "paisano". Esto dará lugar a la emergencia de una nueva sociedad, que busca redistribuir el poder incluyendo como ciudadanos a los inmigrantes y a sus hijos. Una sociedad aluvional, heterogénea y diversa, puede integrarse reforzando y reclamando para sí, ciertos elementos típicos, espaciales, históricos o costumbristas, en suma, todo aquello que le permita diferenciarse de las demás. 


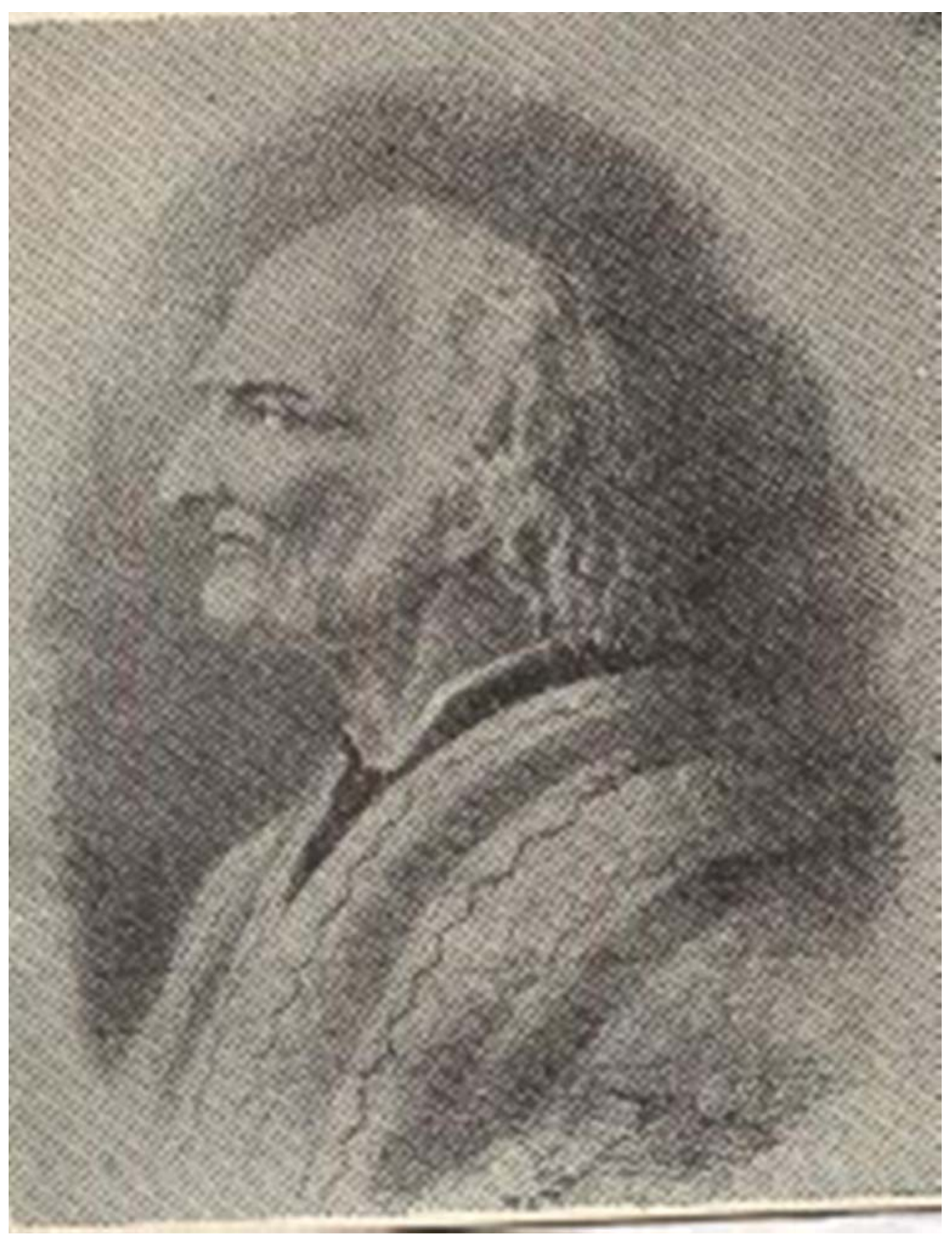

En efecto, nuestro país - al igual que el resto de América - tenía en las últimas décadas del siglo XIX un fuerte componente inmigratorio; el que ha sido calculado en un $40 \%$. Quizás convenga recordar, como lo hace María del Carmen Iglesias, - a partir de Ortega y Gasset - que esa situación nos ha marcado en la elaboración de un tránsito ya que "[...] hemos pasado de la concepción de la patria, como lugar de los padres a la concepción de la nación 
como lugar de los hijos: esto es, de la patria como ayer a la patria como mañana; de la patria como herencia a la patria como quehacer - que puede incluso implicar corregir esa herencia. En una palabra, se da el paso de la patria a la nación" (Maravall, 1999, p. 73).

Ahora será necesario explicar la "historia nacional", dotar al proceso de consolidación de figuras valoradas y acciones simbólicas: la destrucción de las murallas de Montevideo es un símbolo de modernización ${ }^{8}$ de rechazo a lo colonial; la aprobación de la ley parlamentaria por la que se decide construir un monumento a José Artigas en la Plaza Independencia, reconocido ahora como héroe nacional, es también un acto simbólico en este momento. ${ }^{9}$

Partiendo de esta perspectiva, estamos en condiciones ahora de hacer una lectura analítica y genealógica ${ }^{10}$ de algunas expresiones escritas y visuales contenidas en la revista citada.

\section{Ilustración Uruguaya}

Si el cosmopolitismo es fruto de la civilización, la tradición es raiz del verdadero patriotismo [...]. País sin costumbres es país sin fisonomía...

El primer número de la publicación posee diferentes secciones como "Ayer y hoy", "Nuestros grabados", "Sección Científica", una "Sección Literaria", "Correo", comentarios de "Teatro" así como actividades culturales. También anticipa alguna información sobre las fiestas a realizarse el día 25 de agosto en la Plaza Independencia, en conmemoración de la fiesta patria.

El título de la revista es un juego de palabras y símbolos: su logotipo asocia el nombre escrito de la publicación y el escudo nacional. ${ }^{11}$ Este intercepta la mirada que lee con lo que se busca reforzar el sentido nacional a través de la duplicación de lo "uruguayo".

Su nombre la asocia inmediatamente al enciclopedismo francés del siglo XVIII lo que coincide con el intento del país de mostrarse al exterior como un país moderno. ${ }^{12}$ En lo interno revela

8 Es significativo que el edificio de UTU haya sido construido con parte de esas piedras y que re-construidas siguen todavía en pie.

9 Ley 1629, del 5 de julio de 1883, por la que se decide la "erección de una estatua al General Artigas" en la Plaza Independencia.

10 En el sentido de Foucault.

11 Ver logotipo incluido en el artículo.

12 Léase "europeo". 
quizás, la necesidad de convencer "positivamente"13 sobre los cambios que en él se producen.

Además, el movimiento ilustrado es el vínculo entre la Revolución Francesa y las guerras independentistas americanas, principios ideológicos inspiradores de las ideas artiguistas que acaba de ser reconocido como el prócer del país. No hay que olvidar que en este momento el parlamento aprueba la ley que prevé erigir su monumento en la Plaza Independencia ${ }^{14}$ - lo que además es comentado por la propia revista en su contenido escrito - al tiempo que se colocan sus restos en el Panteón nacional, y se emite por primera vez, un sello filatélico con su rostro.

Pensamos que el nombre "Ilustración" remite también posiblemente a la importancia de la iconografía que contiene. Se trata de representaciones visuales de hechos y figuras claves de la historia nacional a través de múltiples grabados comentados, importante en un país en que la palabra escrita no es universal y muchos inmigrantes no pueden comunicarse en el idioma oficial. En este sentido la publicación cumple una función didáctica, de promoción y divulgación de los "rostros de la Historia Patria" similar a la que luego desarrollarían otros artistas americanos como los muralistas mejicanos, por ejemplo.

Creemos que se intenta crear y desarrollar un imaginario social compartido, lo que Castoriadis denomina las representaciones identitarias colectivas, soporte que vehiculiza y facilita el desarrollo de una conciencia nacional compartida.

En apoyo de este análisis importa destacar, que la carátula de la revista fue diseñada por el pintor más emblemático de la pintura histórica: Juan Manuel Blanes, en tanto que el grabador fue Carlos Penoso, maestro en la Escuela de Artes y Oficios.

En relación a ese "frontispicio", la revista redacta que "el artista ha agrupado en él cuanto hay de notable como monumentos y edificios públicos en esta ciudad, caracterizando la composición con la vista del Cerro que se descubre en lontananza. En el centro hay un grupo que significa la riqueza nacional, las artes, las letras, el comercio, dominan a esta composición la estatua ecuestre del General Artigas, tal como ha sido recientemente votada por la legislatura. Ferrocarriles, telégrafos, vapores completan el cuadro elocuente de esta

13 En su doble sentido de positivo y positivismo.

14 En 1884 se colocó la piedra fundamental. El concurso para hacer la escultura fue ganado por Federico Soneira Villademoros en 1885, pero nunca se construyó. El actual monumento es producto de un concurso posterior. 
alegoría, que no dudamos será uno de los trabajos de arte mas justamente apreciados en este número por los conocedores". 15

Comentario escrito de una representación visual en la que Montevideo-capital sintetiza el progreso del país. Se pretende crear "una comunidad en la que lo individual se subsumía en lo colectivo y la unificación de las lealtades se vinculaba a la homogeneización de los universos simbólicos" (Quijada, 1994, p. 50).

A través de la palabra escrita se refuerza la representación visual que ordena y jerarquiza lo que hay que observar.

El sistema urbano y sus grandes monumentos simbólicos (Teatro Solís, por ejemplo) son así, una gramática en la que el estado escribe sus discursos. En ellos se anuda historia y presente, voluntad de deseo y realidad imaginaria. En la composición, el artista ha sabido visualizar que los edificios y monumentos son historia corporeizada y que tal cual un palimpsesto permite crear y re-crear el incipiente sentimiento nacional.

Una forma de decir que la nación es una manera de percibir el mundo, de tal modo que individuos de una misma sociedad puedan pensarse como miembros de una misma comunidad, es la ubicación estratégica del héroe nacional en primer plano, reforzada por la alusión escrita a la ley "recientemente votada".

El análisis del monumento nos impacta: la visión que el artista parece tener del héroe, "tocado con bicornio y uniformado de gala" (Olivieri, 1956, p. 12) al estilo militar francés contradice la tradicional característica del pintor de "fidelidad a lo real [...] en torno a la cual gira su disposición a la pintura histórica". Pero, como explica Peluffo Linari, “[...] a fuerza de 'afrancesar' y 'universalizar' el tipo épico de militares y caudillos [...] les restituye su calidad de 'prohombres' ante los ojos de la tradición culta y doctoral urbana" (Peluffo Linari, 1999, p. 21-26), aspectos que en el mismo sentido refiere el historiador Pivel Devoto: "Los representantes de las élites intelectuales del Río de la Plata disimulaban el hecho de que un general fusilase a los vencidos siempre que lo hiciese en nombre de la civilización y vistiendo uniforme a la francesa; pero eran implacables en cambio cuando un episodio análogo tenía lugar en un ejército sin auditor de guerra, cuyo jefe lucía por atavío un poncho criollo" (Pivel Devoto, 2004, p. 150).

El diseño de Blanes asombra, más aún, cuando con la perspectiva del tiempo transcurrido, sabemos que en los hechos, en la Plaza

15 Ilustración Uruguaya, n. 1, año 1, p. 3. Se aclara además que todas las citas han sido realizadas de acuerdo a la notación de época (incluso tildes) por lo que no han sido modificadas según la grafía actual. 
Independencia (creada por decreto de 1836) la efigie de Joaquín Suárez fue la que se honró desde 1896 hasta 1906. El monumento al prócer fue inaugurado recién el 28 de febrero de 1923, con lo que este frontispicio se adelanta a los sucesos en 40 años. ${ }^{16}$

La portada del periódico exhibe además, en su mitad inferior una fotografía ${ }^{17}$ de la fachada del edificio que albergaba a la Escuela de Artes y Oficios, todavía en la construcción de la calle 18 de julio (hoy demolida, en la intersección con la calle Eduardo Acevedo). Al frente, en formación militar, los alumnos y la Banda. En la fachada del edificio ${ }^{18}$ se destacan nuevamente el Escudo y la Bandera, reforzando y multiplicando los símbolos nacionales.

\section{Otra presencia de Artigas en la revista}

[...] siguió el plan físico de la naturaleza que independizaba, por medio de límites naturales, de los países circunvecinos a ese pedazo privilegiado de suelo, concluyendo la obra de Dios y creando, al fiat de su arrogante valor y su purísimo patriotismo, política y socialmente la nacionalidad uruguaya.

Hay alusiones a hechos de otros países, sobre todo Italia (quizás por la importancia enorme de esa inmigración), a través de artículos como "El terremoto de Cassamicciola". También a otros acontecimientos de actualidad como "La coronación del Czar", o una atracción especial por los avances científicos y técnicos, "El tramvía eléctrico", por ejemplo. Sin embargo, los temas nacionales ocupan el centro de la atención.

En la sección científica un artículo "Sobre la flora de la República: los macachines" y otro sobre "Los utensilios de la Edad de piedra y las supuestas boleadoras charrúas", son indicios de que los orígenes y lo autóctono eran un importante centro de interés.

Un grabado titulado y comentado sobre las "Costumbres nacionales" realizado a partir de un dibujo del ya citado maestro Sommavilla representa un grupo de gauchos en torno a una carreta.

16 El monumento ubicado actualmente en la Plaza Independencia es obra del escultor italiano Zanelli.

17 Según se afirma en la fuente, el original es "un grabado en madera que se fotografió [...]", probablemente realizado por Carlos Penoso, que era entonces, el profesor de Grabados en madera.

18 En ella aparece una fecha grabada poco legible. Según Plinio Torres, la fecha que aparece grabada en la piedra de la fachada indicaría el año 1860. Esto le permite aventurar que sería posible pensar en un funcionamiento del Establecimiento anterior al generalmente admitido. 
Se trata de un conjunto que busca rescatar lo propio, en este caso el uso del "chiripá", ${ }^{19}$ porque "nosotros con la poderosa y rápida facultad de asimilación y por consiguiente de transformación que poseemos vamos cada dia perdiendo nuestro carácter nacional para convertirnos en un pueblo cosmopolita en el cual será difícil dentro de pocos años, adivinar cual es el tipo originario del hijo del país de pura sangre", y agrega "en todos los países del mundo, por civilizados que sean, hay ciertas costumbres nacionales que se conservan y amas se respetan [...]".

Preocupación por desarrollar el espíritu nacional que se explicita nuevamente en el discurso escrito al afirmar "cuando se pierden los perfiles característicos que denotan la nacionalidad en signos esternos, genuinos, propios, originales, algo se ha perdido tambien, de seguro en la pureza de ese sacrosanto sentimiento que se vincula en el corazón y que se llama patriotismo; sentimiento que hace querer mas esta costa del río que separa dos territorios, que la opuesta; que se aferra a una costumbre íntima, diferente de la de los vecinos; que hasta se nutre en las diferencias del uso de una palabra o en los caprichosos giros del lenguaje; por mas que se hable en el continente un mismo idioma".

Signos de que hay necesidad todavía de enfatizar la identidad propia por encima de la identidad latinoamericana.

Texto escrito y visual se complementan en la función didáctica de enseñar la historia por el sentimiento y la imaginación, al decir "como ese gaucho del chiripá eran los que componían las huestes patriotas que derramaron su sangre por constituir libre e independiente esta nacion" (IlustraciónUruguaya, año I, n. 1, p. 3 a 6).

Una cierta nostalgia de inspiración romántica, asentada sobre una visión modernista no le permite sin embargo, analizar críticamente por qué "los gauchos se van" (Ilustración Uruguaya, p. 6).

Como ya vimos, la revista opera a través de la multiplicación de símbolos que se consideran estratégicos para definir lo "uruguayo".

Por eso, la figura de Artigas es sin duda en este primer número, el tema central. Y aparece multiplicada: en la estatua ecuestre imaginada en la carátula; comentada a través de una breve reseña biográfica firmada por Isidoro de María - según Pivel Devoto con imprecisiones - (Pivel Devoto, 2004, p. 64) y como complemento la primer publicación de una litografía del prócer, comentada y explicada, en que se anuncia "Damos un retrato del

19 Se deja constancia que se ha respetado la notación original, en muchos casos sin tilde, $\mathrm{u}$ otras modalidades a diferencia de la actual. 
General Artigas a partir de un diseño realizado por el naturalista francés Bonpland. ${ }^{20}$

Con ostensible orgullo se afirma que el retratista italiano Sommavilla, ${ }^{21}$ "antes de proceder a estampar en la ILUSTRACIÓN URUGUAYA la imagen del padre de la nacionalidad oriental, imagen que era deber y honra de este periódico traer en su carátula" consultó "llevando un croquis (sobre el que está diseñado luego nuestro dibujo) [...]" en relación a los rasgos fisonómicos de Artigas, a distintas personalidades que lo conocieron, ya sea Alejandro Chucarro o a familiares directos como Rosalía Artigas de Ferreira.

También se afirma que el retrato original que sirvió de base tenía "irregularidades y aún monstruosidades", por lo que "[...] nuestro hábil dibujante, ha adivinado lo que el naturalista pretendió, y aún se esforzó por ejecutar, y sin tocar lo que llamaremos el fondo típico de la imagen, solamente ha corregido los defectos y errores del dibujista empírico. El cráneo, antropológicamente imposible, las cuencas de los ojos trazadas casi en un arco de círculo absoluto, la nariz deformemente encorvada, la barba saliente en un ángulo agudo, perfiles todos más ornitológicos que humanos, han sido regularizados, corregidos, dulcificados, humanizados [...]", y agrega que se ha optado por presentar sólo la cabeza para condensar "[...] todo el pensamiento que debe circundar como un nimbo de luz, la faz de los hombres culminantes".

Como el pintor que trabajó al natural "[...] con naturalismo hiriente, había detallado con rasgos que presentaban más que al ideal de la personificación de Artigas, al pordiosero miserable y harapiento" se ha conservado en el retrato "[...] el tradicional poncho americano [...] por que expresa con mas fuerza el carácter eminentemente nacional del héroe [...], porque es de absoluta verdad histórica, siendo el tipo de Artigas el del hombre modesto y sobrio en el vestir".

Para concluir la presentación del retrato dice que no cree "[...] que esta deba ser la figura definitivamente consagrada del paladín de la independencia de este país [...] más de patriarca que de guerrero, la imagen llamada a perpetuar gráfica y oficialmente la memoria del héroe [...]", porque "el ara sagrada de las glorias nacionales, reclama... la personificación viril del héroe [...]", y

Según se ha demostrado actualmente, parece haber sido realizada por Demersay.

21 El artista mencionado se instala en el país en 1882. Ha vivido en Italia el proceso del "Rissorgimento" que finaliza con la unificación italiana (1870) por lo que es probable, que en él estuviera muy presente la importancia de los elementos nacionalizantes y la función del arte en ese proceso. Muere en Montevideo en 1944. 
agrega "hoy que se ha decretado una estatua que represente al paladín de la independencia, es necesario crear, pero por medio de un proceso serio y rigurosamente documentado, la figura real del General Artigas en los años gloriosos en que, con su brillante espada, trazaba los límites de esta nación, y en el porvenir la apoteosis de su inmortalidad"22 (Ilustración Uruguaya, año I, n. 1, p. 3).

En realidad el dibujo realizado por Sommavilla a partir del retrato de Demersay es una de las primeras versiones nacionales del retrato de Artigas y según Olivieri la primera litografía, lo que otorga al documento un valor especial.

Pero, sobre todo nos importa resaltar que en la revista parecen coexistir sin conflicto, dos mundos imaginarios diferentes, visibles a través de las dos representaciones de Artigas ejecutadas independientemente por Blanes y Sommavilla.

Presentadas en forma casi superpuesta, y mostrando visiones tan disímiles del prócer, cuesta creer que la contradicción no haya sido percibida por los actores-artistas y sobre todo por los lectores involucrados.

La representación de Blanes, uruguayo pero formado en Europa, lo muestra como un militar europeo, según Peluffo para lograr la aceptación de la élite dirigente; la versión de Sommavilla, italiano que ha vivido el proceso nacionalista en Italia, reclama mantener "el carácter eminentemente nacional del héroe" a través del poncho, y afirma la necesidad de reconstruir la figura de un modo "rigurosamente documentado" aunque hace - y lo expresa sus propias modificaciones a un retrato tomado del original.

Si la versión de Blanes conformaba a la "tradición culta y doctoral": ¿A quién representaba la versión de Sommavilla, trabajando desde la Escuela de Artes y Oficios?

Recordemos que esta Escuela era el refugio de jóvenes de bajos recursos y hasta delincuentes, a los que el estado reservaba un lugar a través del aprendizaje de un oficio.

Es claro que estos documentos develan la operática de micropoderes contrapuestos al pretender trasmitir un "héroe" capaz de satisfacer a los distintos grupos sociales que ya conformaban la sociedad uruguaya; también, que casi ciento treinta años después pocos uruguayos reflexionan sobre la "verdad" de esas representaciones "oficiales" de Artigas, hoy naturalizadas.

¿La representación social de Artigas que los uruguayos compartimos habrá sido producto de una negociación que logró cristalizar en algún punto intermedio de estas dos visiones?

22 La página 4 incluye la litografía analizada. 
Para responder esta pregunta sería necesario realizar estudios de mayor envergadura.

Sin embargo, las conclusiones no parecen simples. Por lo pronto, es necesario relacionar la ideología europea de la época presente en esta publicación contiene las contradicciones propias de la época: romanticismo y liberalismo, positivismo y nacionalismo, junto a algunos rasgos propios de esta última parte del siglo XIX europeo. Preocupado por la diferencia del "otro" y sus culturas, inicia estudios "científicos" acerca de la raza y comienza a preocuparse por el color de la piel o de los ojos: Se habla del "[...] hijo de pura sangre" y no es casual que en el artículo comentado sobre la litografía de Artigas, se haga especial hincapié en "la hermosa y sonrosada tez" o en "[...] la luz vivísima de sus ojos azules".

El somero análisis de algunos aspectos contenidos en esta publicación nos ha permitido entrelazar los procesos de consolidación de las dos identidades: la nacional y la institucional, al mismo tiempo nos ha aproximado a la comprensión del aporte de nuestra organización-institución en ese doble proceso.

El juego contrapuesto de poderes e intereses que se manifiestan al presentar "al héroe" permiten visualizar el origen de una representación social hoy cristalizada por efecto conjunto de distintas instituciones, sobre todo las educativas, que encubren su carácter sociohistórico y por lo tanto de construcción social.

Al mismo tiempo, pudimos constatar como la representación de hechos y personajes históricos a través de una iconografía que adopta parte del molde europeo al tiempo que denuncia la existencia de mundos imaginarios divididos, no impide a la Ilustración Uruguaya anticipar en el país un discurso de nacionalismo moderno que tomando a la figura de Artigas como centro se afilia a un estado-nación preocupado por consolidar la mutualidad del idioma, del territorio, la comunidad y la cultura.

\section{Referencias bibliograficas}

Anderson, Benedict. Comunidades imaginadas. Reflexiones sobre el origen y la difusión del nacionalismo. Mexico: FCE, 1993.

Castoriadis, Cornelius. La Institución imaginaria de la Sociedad. Marxismo y Teoría revolucionaria. Barcelona: Edit. Tesquets, 1983.

Chiaramonte, José C. Ciudades, provincias, Estados: orígenes de la Nación Argentina (1800 1846). Buenos Aires: Edit. Ariel, 1997. 
Chiaramonte, José Carlos. La formación de los Estados Nacionales de Iberoamérica. Boletín n. 15 del Instituto de Historia Argentina y Americana, 3ra. Serie, 1er. semestre de 1997 FCA, p. 143 a 165.

Foucault, M. Vigilar y castigar. México: Siglo XXI, 1976.

Guerra, F. et al. (coord). Imaginar la Nación. Cuadernos de Historia Latinoamericana, n. 2, Edit. Minister Hamburg, Lit., 1994.

Guerra, Francois Xavier. Modernidad e independencias. Ensayos sobre las revoluciones hispánicas. España: Edit. MAPFRE, 1992.

Iglesias, Ma. del Carmen. Introducción. In: Maravall, A. (ed). Estudios de Historia del pensamiento español (siglo XVII). Madrid: Ediciones Cultura Hispánica, 1999.

Quijada, Monica. Imaginar la Nación. Cuaderno de Historia Latinoamericana, n. 2, 1994, cap. 7.

Olivieri, Carlos. Rincones de la Historia. Montevideo: Edit. Prometeo, 1956.

Peluffo Linari, Gabiel. Historia de la Pintura Uruguaya. T. I El imaginario Nacional Regional (1830-1930). Montevideo: EBO, 1999.

Pivel Devoto, Juan E. De la leyenda negra al culto artiguista, Biblioteca Artigas, Col. de clásicos uruguayos, vol. 171, A.G.N, Montevideo, 2004.

\section{Revistas}

Ilustración Uruguaya, 1883-1885, Biblioteca Nacional.

\section{Archivos}

Archivo del Centro Cultural "Figari" (AUTU).

Archivo General de la Nación (AGN).

Archivo del Poder Legislativo (BPL).

Recebido em 27 de julho de 2007. 